\title{
OCLUSÃO DA VEIA CENTRAL DA RETINA APÓS TRATAMENTO COM IMUNOGLOBULINA HUMANA ENDOVENOSA
}

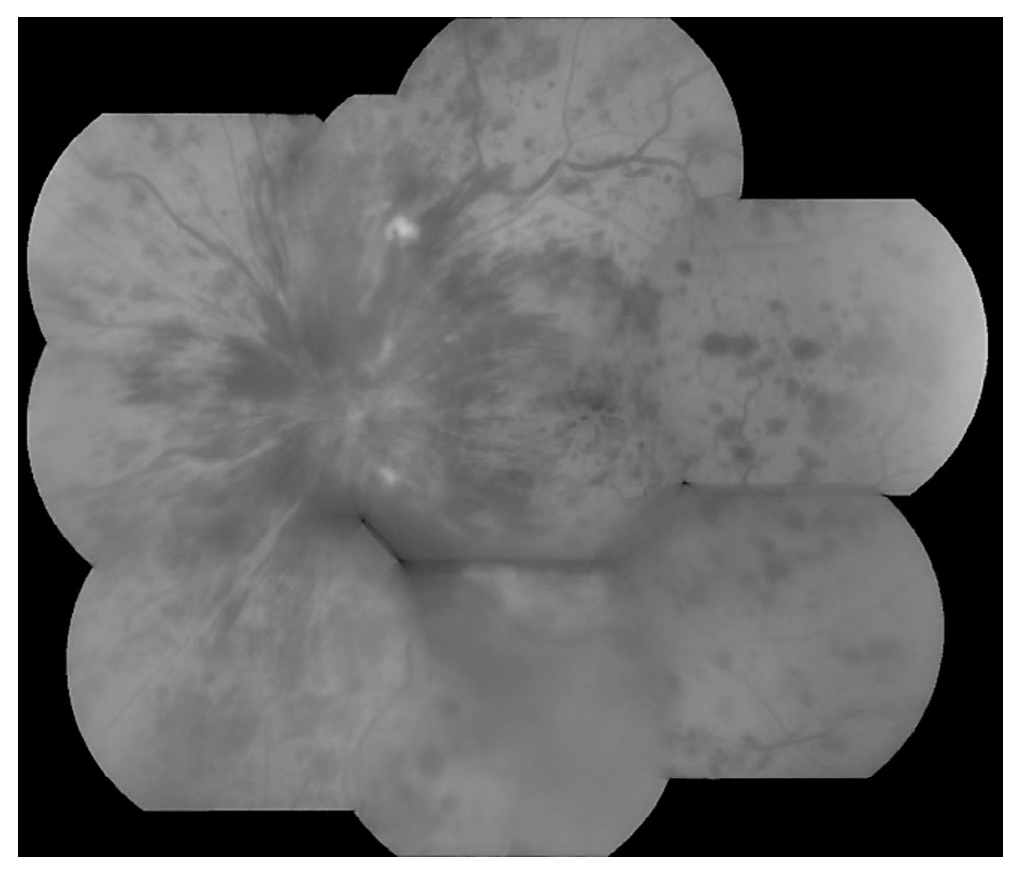

O caso clínico apresentado é de um paciente do sexo masculino, 57 anos, hipertenso, com diagnóstico de neuropatia motora multifocal (MMN), que usava iosartan potássico $50 \mathrm{mg} /$ dia associado a hidroclorotiazida $12,5 \mathrm{mg} /$ dia, com bom controle pressórico e fazia tratamento com imunoglobulina humana endovenosa na dose de $\mathrm{I} \mathrm{g} / \mathrm{Kg} /$ dia por dois dias consecutivos a cada cinco semanas para controle da neuropatia. Apresentou baixa de acuidade visual severa e abrupta no olho esquerdo cinco dias após a quarta sessão de imunoglobulina. Ao exame oftalmológico apresentava acuidade visual 20/20 no olho direito e 20/400 no olho esquerdo; reflexos pupilares normais; pressão intra-ocular de $12 \mathrm{mmHg}$ em ambos os olhos; exame fundoscópico normal no olho direito e, no olho esquerdo, apresentava hemorragias retinianas superficiais difusas nos quatro quadrantes, asssociadas a tortuosidade e dilatação venosa, além de manchas algodonosas e edema retiniano. Foi feito o diagnóstico de oclusão da veia central da retina (OVCR) no olho esquerdo. A oclusão da veia central da retina é um distúrbio oftalmológico relativamente comum, caracterizado por hemorragias retinianas nos quatro quadrantes, associado a dilatação e tortuosidade venosa. É secundária à formaçãa de trombo na região da lâmina crivosa. Ocorre mais comumente em indivíduos acima de 50 anos, associada a alterações sistêmicas como hipertensão arterial e diabetes, ou a alterações oculares, como o glaucoma primário de ângulo aberto. Alterações sistêmicas que causem aumento da viscosidade sangüínea também podem estar associadas a OVCR. Policitemia Vera, mieloma múltiplo, macroglobulinemia de Waldestrom são exemplos bem conhecidos. Recentemente, a imunoglobulina humana endovenosa começou a ser utilizada no tratamento de neuropatias periféricas desmielinizantes. É sabido que seu uso pode aumentar o risco de acidentes tromboembólicos. Dois casos de oclusão da veia central da retina associados a este tratamento foram relatados na literatura mundial. No presente caso, não conseguimos comprovar a relaçãa causal da imunoglobulina humana endovenosa em altas doses com a oclusão da veia central da retina. No entanto, acreditamos ser importante alertar quanto a esta possibilidade, assim como identificar e tratar fatores de risco cardiovasculares em pacientes submetidos a tratamento com imunoglobulina humana endovenosa.

\section{Guilherme lima Palácio, Alberto Alain Gabbai, Cristina Muccioli, Rubens Belfort Jr}

\section{Universidade federal de São Paulo - Escola Paulista de Medicina}

